\title{
in Technology
}

\section{Editorial}

\section{Hydrogels: Next Generation Atmospheric Water Harvesting Materials}

Rohan S. Dassanayakea, ${ }^{a}$ and Renuka Nilmini ${ }^{b}$

a Department of Biosystems Technology, Faculty of Technology, University of Sri Jayewardenepura, Homagama 10200, Sri Lanka

b Department of Materials and Mechanical Technology, Faculty of Technology, University of Sri Jayewardenepura, Homagama 10200, Sri Lanka

Email correspondence: rdassanayake@sjp.ac.lk (R. S. Dassanayake)

Received: 20 April 2021; Accepted: 15 May 2021; Published: 31 May 2021

\section{Hydrogels could harvest atmospheric moisture to produce clean drinking water mitigating the global water scarcity woes in future.}

Hydrogel is a three-dimensional (3D) cross-linked network of a hydrophilic polymer, which can absorb and retain a large amount of water while maintaining its structure. Generally, a hydrogel contains approximately $10 \%$ of water by total weight or volume and can be classified based on the source (natural or synthetic), polymeric composition (homopolymeric, copolymeric or multipolymeric), polymeric configuration (crystalline, semi-crystalline or amorphous), network electrical charge (neutral, anionic, cationic and ampholytic)[1]. Hydrogels have attracted significant attention due to their unique properties, including relative abundance, renewability, flexibility, surface functionalization, and tunable chemical and mechanical properties. Therefore, they have been applied in a broad spectrum of fields such as energy, environmental, agriculture, medicine, food, and engineering $[1,2]$.

Over the last few decades, global water demand has drastically 
increased worldwide due to numerous factors, including population growth, urbanization, economic growth, and high food and energy demand. It has been reported that around two thirds of the world's population face water scarcity for a month annually, and half of the world's population could experience water scarcity in the next four years [3]. The main reasons for the water scarcity include global climate change and anthropogenic activities such as water pollution, poor management of water resources, conflicts, and development projects. Technologies like desalination of seawater are associated with many setbacks such as high operational, labor, and transportation costs, making them less popular alternatives to address water scarcity. Interestingly, the earth's atmosphere holds approximately 1300 billion tons of freshwater, which is equivalent to about $10 \%$ of freshwater in all lakes on earth [4, 5]. Recently, state-of-the-art atmospheric water harvesting $(\mathrm{AWH})$ technologies have emerged as a promising approach to harvest liquid water from the air. In 2018, AWH technologies started their journey after a breakthrough made by $\mathrm{Yu}$ and Zhao from the Cockrell School of Engineering at the University of Texas at Austin, Austin, Texas, USA, with the development of the solar-powered water purification system using hydrogels that cleans water from any source using solar energy.

Several hygroscopic hydrogels have been recently considered as novel AWH materials. For instance, Kallenberger and coworkers prepared calcium incorporated alginate-derived hydrogel with $660 \mathrm{~kg}$ of water absorption per cubic meter of the hydrogel from the air at 10 mbar water vapor pressure and at $28{ }^{\circ} \mathrm{C}$ temperature [6]. A composite hydrogel prepared from polyacrylamide with calcium chloride and carbon nanotubes absorbs $0.74 \mathrm{~g}$ of water per $1 \mathrm{~g}$ of the hydrogel at $35 \%$ relative humidity (RH) [2]. Zhou et al. reported a solar powered atmospheric water irrigation system based on super moisture absorbent gels (SMAG) prepared from thermoresponsive poly( $\mathrm{N}$-isopropylacrylamide) and 
reported the harvesting of $4 \mathrm{~g}$ of water per gram of fully dried SMAG sample $(\mathrm{g} / \mathrm{g})$ at $90 \% \mathrm{RH}$ [7]. The authors also exhibited the water liquefaction of $6.7 \mathrm{~g}$ per $1 \mathrm{~g}$ of dry SMAG prepared from chloride-doped polypyrrole and poly-N-isopropylacrylamide at $90 \% \mathrm{RH}$ [8].

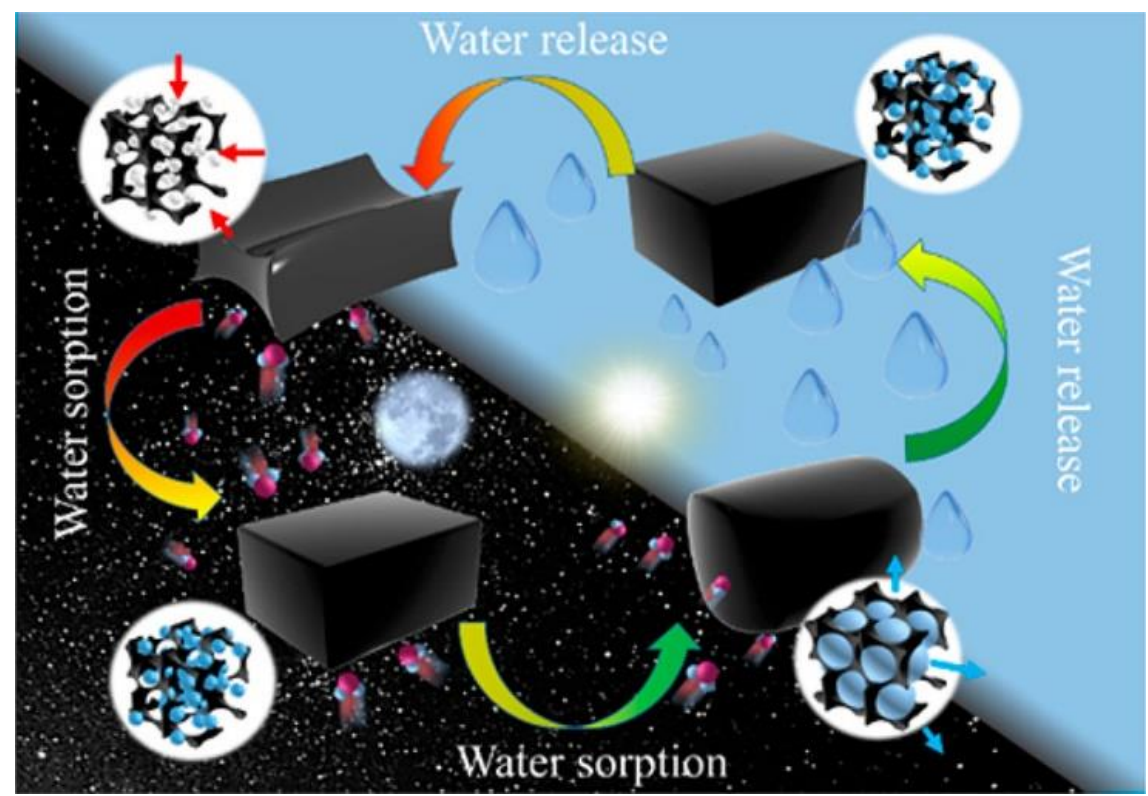

Figure 1. Schematic diagram of the hybrid hydrogel as AWG. Water vapor can be captured at night time and released during day time under assistance of sunlight. [Ref. 5] Environ. Sci. Technol. 2018, 52, 19, 11367-11377, doi.org/10.1021/acs.est.8b02852, Copyright permission under AC.

In summary, hydrogels, also known as gel-polymers, can absorb and retain large amounts of water and release the water upon heating. They possess excellent atmospheric water harvesting (AWH) abilities over a wide range of $\mathrm{RH}$ covering arid deserts to inland dry regions. Therefore, hydrogels could potentially act as future water reservoirs and help address global water scarcity.

\section{References}

[1] E. M. Ahmed. Hydrogel: Preparation, characterization, and applications: A review. J. Adv. Res. 2015, 6, 105-121.

[2] M.Mahinroostaa, Z. J. Farsangib, A. Allahverdia, Z. Shakoori. Hydrogels as intelligent materials: A brief review of synthesis, properties and applications. Mater. Today Chem., 2018, 8, 42-55.

[3] M. M. Mekonnen, A. Y. Hoekstra. Four billion people facing severe water scarcity. Sci. Adv. 2016, 2, e1500323.

[4] J. Ju, H. Bai, Y. Zheng, T. Zhao, R. Fang, L. Jiang. A multi-structural and multi- 
functional integrated fog collection system in cactus. Nat. Commun. 2012, 3, 1247.

[5] R. Li, Y. Shi, M. Alsaedi, M. Wu, L. Shi, P. Wang. Hybrid hydrogel with high water vapor harvesting capacity for deployable solar-driven atmospheric water generator. Environ. Sci. Technol. 2018, 52, 11367-11377.

[6] P. A. Kallenberger, M. Fröba, Water harvesting from air with a hygroscopic salt in a hydrogel-derived matrix. Commun. Chem. 2018, 1, 28.

[7] X. Zhou, P. Zhang, F. Zhao, G. Yu. Super moisture absorbent gels for sustainable agriculture via atmospheric water irrigation. ACS Mater. Lett. 2020, 2, 1419-1422.

[8] F. Zhao, X. Zhou, Y. Liu, Y. Shi, Y. Dai, G. Yu, Super moisture-absorbent gels for all-weather atmospheric water harvesting. Adv. Mater. 2019, 31, 1806446. 